\title{
To give or not to give? Are we ready to use noninvasive monitors to guide fluid management in cardiothoracic surgical patients?
}

\author{
Rakesh C. Arora, MD, PhD, FRCSC
}

See related article on pages 3139-45.

Ensuring adequate cardiac output to meet the metabolic demands of the body's tissues is the central tenet of management for the postoperative cardiac surgical patient. ${ }^{1-3}$ The most common therapy in the early postoperative period to promote this is the use of intravenous fluids. Fluids are typically infused with the goal of optimizing the FrankStarling relationship of ventricular end-diastolic volume (preload) and stroke volume to optimize cardiac output and thus forward flow and oxygen delivery. ${ }^{4}$ A patient's condition may be deemed fluid "responsive" if the heart responds to an increase filling volume by increasing its stroke volume and subsequent cardiac output. ${ }^{5}$ The importance of using this therapy appropriately is exemplified by recent publications in which excessive fluid administration was associated with increased edema, acute kidney injury, and mortality. ${ }^{4,6-10}$ Conversely, harm can also occur with inappropriate use of inotropes or vasopressors in the inadequately volume-resuscitated patient. ${ }^{5}$ It is therefore important for the bedside clinician to have a reliable means of accurately determining an individual patient's optimal intravascular volume.

The determination of a patient's need for fluid administration has traditionally relied on "static" estimation of intravascular blood volume by the assessment of the right atrial or central venous pressure through invasive catheters such as right atrial or pulmonary arterial catheters. The potential limitations and pitfalls of these monitoring tools in the cardiothoracic intensive care unit are increasingly apparent. ${ }^{11,12}$ As described by Kang and colleagues in their article in this issue of the Journal, the challenge of appropriate fluid administration for the postoperative cardiac surgical patient is complex because of the underlying cardiac pathology and coexisting comorbidities and medications.

\footnotetext{
From St Boniface Hospital/I.H. Asper Institute, Winnipeg, Manitoba, Canada.

Disclosures: R.C.A. is the president of the American Delirium Society and has an unrestricted educational grant from Pfizer Canada, Inc, for work unrelated to this article.

Received for publication Oct 13, 2014; accepted for publication Oct 14, 2014

Address for reprints: Rakesh C. Arora, MD, PhD, FRCSC, St Boniface Hospital/I.H. Asper Institute, CR3012, 369 Tache Ave, Winnipeg, Manitoba, Canada, R2H 2A6

(E-mail: rakeshcarora@gmail.com).

J Thorac Cardiovasc Surg 2014;148:3146-7

$0022-5223 / \$ 36.00$

Copyright (c) 2014 by The American Association for Thoracic Surgery

http://dx.doi.org/10.1016/j.jtcvs.2014.10.067
}

Dynamic indicators of alterations in preload, such as respiratory changes in right atrial pressure, arterial pressure, and aortic blood velocity, may be useful for predicting a patient's responsiveness to fluid administration. ${ }^{4}$ As such, there has been substantial interest in understanding the utility of monitoring tools that permit the "dynamic" estimation of recruitable cardiac output, such as pulse pressure variation, stroke volume variation, end-expiratory occlusion test, and inferior vena cava collapsibility by bedside ultrasonography. ${ }^{1,5,13}$ Equally important, many of these newer technologies do not require invasive, intravascular catheter placement and permit continuous, beat-to-beat variability assessment. In a recent meta-analysis, Aya and associates ${ }^{2}$ examined the effectiveness of perioperative monitoring and manipulation of hemodynamic parameters in the management of cardiac surgical patients. Of the 5 trials meeting the criteria to be included in their analysis, only 1 reported the use of a pulmonary artery catheter, with the remainder using dynamic cardiac output monitoring devices in the intervention arms of their respective studies. Aya and colleagues ${ }^{2}$ reported that the use of these devices to guide their therapy reduced morbidity and hospital stay (though not mortality).

The current study by Kang and colleagues is intended to provide new information on a noninvasive cardiac output (NICOM) device that measures bioelectric impedance in patients undergoing isolated aortic valve procedures. Specifically, Kang and colleagues sought to understand the relationship of the bioreactance NICOM device across a range of mechanical ventilation tidal volumes and positive endexpiratory pressure levels. They used a passive leg raise to assess patient baseline fluid responsiveness. The passive leg raising test, which delivers a reversible endogenous fluid challenge by increasing venous return, serves to highlight that simple bedside maneuvers can aid in the determination of the heart sensitivity to alterations in preload.

The main clinical impact of the findings of Kang and colleagues is that higher levels of positive end-expiratory pressure (a positive end-expiratory pressure of $10 \mathrm{~cm} \mathrm{H}_{2} \mathrm{O}$ ) altered the optimal cutoff value for fluid responsiveness, as measured by the studied device. Kang and colleagues therefore advocate that careful interpretation of stroke volume variation for fluid management is required to prevent volume overload under different mechanical ventilation conditions. Their observations are limited, however, to relatively young patients undergoing isolated aortic valve replacements. It is unclear whether this relationship would persist in patients in with abnormal left atrial pressure (such as those with severe mitral valve disease or poor left ventricular function). 
Furthermore, it is unclear what impact chest wall edema or pleural effusions would have on the accuracy of the bioimpendence measured by the studied NICOM device. Finally, Kang and colleagues allocated patients to the volume "responsive" group after an observed 7\% increase in measured cardiac output by the studied NICOM device in response to a straight leg raise, but they did not use other monitoring devices (thermodilution, pulse pressure variation, or other) to validate the NICOM definition of volume responsiveness in this patient population.

Nonetheless the results presented in the article of Kang and colleagues serve as a reminder that despite the potential value of NICOM devices to assist with goal-directed therapy, the use of the information provided by these tools needs to be carefully considered within the clinical context of each patient and variable conditions that are constantly changing (such as mechanical ventilator settings). Further validation studies across a wide variety of cardiopulmonary pathologies are required to determine the utility of NICOM devices in the care of the complex postoperative cardiac surgical patient.

I acknowledge the assistance and content provided by Drs Rohit Singal (Winnipeg, Alberta, Canada), Sean M. Bagshaw (Edmonton, Alberta, Canada), and Eric Seely (San Francisco, Calif) in the generation of this commentary.

\section{References}

1. Alhashemi JA, Cecconi M, Hofer CK. Cardiac output monitoring: an integrative perspective. Crit Care. 2011;15:214.

2. Aya HD, Cecconi M, Hamilton M, Rhodes A. Goal-directed therapy in cardiac surgery: a systematic review and meta-analysis. Br J Anaesth. 2013;110:510-7.
3. Charlson M, Isom O. Clinical practice. Care after coronary-artery bypass surgery. $N$ Engl J Med. 2003;348:1456-63.

4. Michard F, Teboul JL. Predicting fluid responsiveness in ICU patients: a critical analysis of the evidence. Chest. 2002;121:2000-8.

5. Singh S, Kuschner WG, Lighthall G. Perioperative intravascular fluid assessment and monitoring: a narrative review of established and emerging techniques. Anesthesiol Res Pract. 2011;2011:231493.

6. National Heart, Lung, and Blood Institute Acute Respiratory Distress Syndrome (ARDS) Clinical Trials Network, Wiedemann HP, Wheeler AP, Bernard GR, Thompson BT, Hayden D, deBoisblanc B, et al. Comparison of two fluid-management strategies in acute lung injury. $N$ Engl J Med. 2006; 354:2564-75.

7. Brandstrup B, Tønnesen H, Beier-Holgersen R, Hjortsø E, Ørding H, LindorffLarsen K, et al. Danish Study Group on Perioperative Fluid Therapy. Effects of intravenous fluid restriction on postoperative complications: comparison of two perioperative fluid regimens: a randomized assessor-blinded multicenter trial. Ann Surg. 2003;238:641-8.

8. Bayer O, Schwarzkopf D, Doenst T, Cook D, Kabisch B, Schelenz C, et al. Perioperative fluid therapy with tetrastarch and gelatin in cardiac surgery - a prospective sequential analysis. Crit Care Med. 2013;41:2532-42.

9. Yunos NM, Bellomo R, Hegarty C, Story D, Ho L, Bailey M. Association between a chloride-liberal vs chloride-restrictive intravenous fluid administration strategy and kidney injury in critically ill adults. JAMA. 2012;308: 1566-72.

10. Zarychanski R, Abou-Setta AM, Turgeon AF, Houston BL, McIntyre L, Marshall JC, et al. Association of hydroxyethyl starch administration with mortality and acute kidney injury in critically ill patients requiring volume resuscitation: a systematic review and meta-analysis. JAMA. 2013;309: 678-88.

11. Shippy CR, Appel PL, Shoemaker WC. Reliability of clinical monitoring to assess blood volume in critically ill patients. Crit Care Med. 1984;12: 107-12.

12. Marik PE, Baram M, Vahid B. Does central venous pressure predict fluid responsiveness? A systematic review of the literature and the tale of seven mares. Chest. 2008; $134: 172-8$

13. Thiele RH, Bartels K, Gan TJ. Cardiac output monitoring: a contemporary assessment and review. Crit Care Med. September 23, 2014 [Epub ahead of print]. 